\title{
LAS FAMILIAS TRANSNACIONALES
}

\author{
AgUilar DíAZ, Richard ${ }^{74}$
}

SUMARIO. 1. Introducción. - 2. Los cambios en los modelos de familia, factores. -3. La familia en el ordenamiento jurídico español. - 4. Extensión del concepto de familia. - 5. La familia en el ámbito internacional. - 6. El derecho a vivir en familia y el Derecho a la Libre circulación de personas. - 7. Conclusiones.Bibliografía

\section{RESUMEN}

Considerando la constante evolución del modelo de familia tradicional por factores interestatales (personales, jurídicos y económicos) e internacionales (migraciones), que originan nuevos modelos de familia, resulta necesario conocer si estos modelos gozan o no de reconocimiento jurídico y por ende de la protección familiar dispuesta por la constitución política del Estado y leyes pertinentes.

Palabras clave: Familia, organización, reconocimiento jurídico, migraciones, protección familiar, globalización, familia trasnacional, matrimonio, convivencia, parejas mixtas.

\section{ABSTRACT}

\section{Key words:}

${ }^{74} 1$ Abogado del Ilustre Colegio de Abogados de Barcelona. Becario del Máster en Derecho de Familia e Infancia de la Universidad de Barcelona. Posgraduado en Derecho Diplomático y Consular. Licenciado en Derecho por la Universidad de Barcelona. Colaborador distinguido de la Asociación para la Defensa de los Derechos de la Infancia y la Adolescencia (ADDIA). 


\section{Introducción}

En el presente estudio analizaremos la situación actual de las familias y su proyección en el ámbito estatal, europeo e internacional.

Partiendo de la base que el modelo de familia tradicional se encuentra en constante evolución producto a diversos factores interestatales (personales, jurídicos y económicos) e internacionales (flujos migratorios) y que estos originan nuevos modelos de familia o de organización familiar, los cuales interactúan en nuestra sociedad.

Analizaremos si estos modelos gozan o no del reconocimiento jurídico y por ende de la protección familiar dispuesta en el artículo 39 de la Constitución española (CE).

Asimismo, teniendo en cuenta que vivimos en un mundo globalizado, en donde las políticas y flujos migratorios de corte económico y laboral, inciden en la esfera familiar tanto nivel estatal como internacional. Analizaremos también la protección de la familia, especialmente cuando ésta presenta un elemento de extranjería, así como cuando se da el traslado de la misma a un tercer país con el objetivo de afincarse en dicho Estado de destino. Derivados de estos últimos supuestos, se configura lo que jurídicamente se denominan familia transnacional que son el eje principal del presente estudio.

\section{Los cambios en los modelos de familia, factores}

Si bien es cierto el modelo tradicionalmente aceptado es el conformado por padres e hijos, en el que interactúan por un lado las relaciones paterno filiales y de otro obligaciones parentales; hablamos pues de la familia nuclear, modelo mayoritariamente aceptado en los ordenamientos jurídicos europeos, entre ellos España.

La sociedad evoluciona constantemente y con ello los modelos de familia. Así pues podemos afirmar que existen diversos factores que propician los cambios dentro de la esfera familiar. Entre los factores que sirven como base de estos nuevos modelos de familia podemos indicar a los siguientes:

La integración de la mujer en el mercado laboral. Se ha superado el estereotipo en el que la mujer era quien se quedaba en casa para cuidar del hogar y los niños. Actualmente ambos progenitores trabajan y necesitan ayuda externa para solventar, entre otras, responsabilidades como el cuidado de los hijos.- Los Cambios en los roles de familia o tareas domésticas. El ritmo social y económico actualmente ha conducido a nuevas organizaciones en la esfera familiar y reparto de tareas domésticas.

Las crisis familiares (la separación, nulidad y divorcio) generan nuevas situaciones de organización y residencia, como por ejemplo, disuelto el vínculo matrimonial, uno o ambos ex cónyuges se ven obligados a regresar, junto con los hijos, a la casa de los padres, iniciando con esto una nueva relación familiar y convivencial.- Los flujos migratorios que responden a fines laborales y/o económicos en donde uno de los miembros de la familia emigra a un tercer país iniciando así su proyecto migratorio. Vistos los factores citados, es importante tener en cuenta las clasificaciones de familia hechas por los sociólogos, las cuales ofrecen una lista de modelos de familia basadas en la residencia. Los cuales son: unipersonal, sin núcleo conyugal, mono parental, pareja sin hijos, pareja con hijos dependientes, grupos 
recompuestos, familias extensas, familias múltiples, familia mono parental y familia compuesta (RICO IÑIGO, Marta).

\section{La familia en el ordenamiento jurídico español}

En la CE de 1978 en sus artículos 32.1 y 39.1, el primero reconoce el derecho a contraer matrimonio y el segundo establece la protección social, económica y jurídica a la familia. Con base en lo anterior, el Tribunal Constitucional español (TC) en su ejercicio jurisdiccional interpretativo de ambos preceptos, concluía que la protección otorgada a la familia se circunscribía únicamente a la familia matrimonial. Actualmente la doctrina constitucional ha superado dicha postura, resolviendo que dichos apartados deben interpretarse aisladamente.

En el ámbito estatal, es importante citar la existencia del sistema matrimonial español regulado en el Código Civil estatal (CC) en sus artículos 42 y siguientes. En los que apreciamos un sistema matrimonial mixto, ya que coexisten dos tipos de matrimonio: el matrimonio civil en su art. $44 \mathrm{CC}$ y el matrimonio religioso con reconocidos efectos civiles establecido en el art. $59 \mathrm{CE}$ (SATORRAS FIORETTI, Rosa $\mathbf{M}^{\mathbf{a}}$ ). Ambos matrimonios producen efectos una vez cumplido el requisito de inscripción en el Registro Civil siguiendo, siguiendo lo establecido en el art. $61 \mathrm{CE}$.

Continuando con la regulación matrimonial, es oportuno citar la presencia de la legislación autonómica, toda vez que España al ser un Estado unitario plurilegislativo y siguiendo lo establecido por el art. 49.1.8 $\mathrm{CE}$, se reconoce la competencia legislativa a las Comunidades Autónomas (CCAA) en asuntos de ámbito civil. Citaremos especialmente a la legislación civil catalana, específicamente la Ley 25/2010, de 29 de julio, del libro Segundo del Código Civil de Cataluña, relativo a la persona y a la familia.

\section{Extensión del concepto de familia}

Siguiendo lo expuesto en el anterior apartado I, donde hicimos referencia sobre las Nuevas manifestaciones en la organización familiar con la consecuente aparición de Nuevos modelos de familia, y la necesidad de regular estas nuevas situaciones de Convivencia dentro del ordenamiento jurídico español. Es preciso recordar que el Derecho no es ajeno a estos cambios sociales y familiares por lo que el legislador estatal debe responder a estas demandas.

En cuanto a los cambios en los modelos de familia, teniendo en cuenta las crisis matrimoniales como las relaciones de convivencia, en sus diferentes modalidades, generan nuevos supuestos en el ámbito familiar, por lo que es menester formular las siguientes cuestiones: ¿el ordenamiento jurídico español reconoce a los nuevos modelos de convivencia como una familia?, ¿el sistema legal contempla dicho reconocimiento y por ende los nuevos modelos de familia son beneficiarios de la protección al mismo nivel que la familia matrimonial y nuclear? La respuesta, en mi opinión, es parcialmente afirmativa, toda vez que de las 17 comunidades autónomas que conforman el Estado español, sólo 13 de ellas han regulado lo referente a las parejas de hecho y uniones estables de pareja (VILLAGRASA ALCAIDE, Carlos) y su tentativa de equiparación de efectos al matrimonio, lo cual evidencia la ausencia y tan necesitada legislación estatal al respecto. 
Una parte de la doctrina se ubica a favor de concebir a las parejas de hecho o uniones estables de pareja de manera similar a la de un matrimonio a prueba por tanto se entiende que hablamos de un modelo de familia no matrimonial o more uxorio. Y la otra concepción doctrinal se decante por equiparar los efectos de dichas parejas a los del matrimonio.

De todo lo anterior, y con especial referencia a las familias transnacionales la Ley Orgánica 4/2000, de 11 de enero, sobre derechos y libertades de los extranjeros en España y su integración social (LODYLE), de su dispositivo 17.1.b. podemos sostener que el legislador incluye al grupo recompuesto como modelo de familia, lo cual permite a los hijos del residente y del cónyuge como beneficiarios de la reagrupación familiar.

La existencia de estos tipos de familia basados en la convivencia y la solidaridad han sido reconocidas por el TC, entre otras, en su sentencia 222/1992, como un modelo de familia y por ende reconoce a sus integrantes como beneficiaros de la protección dispuesta por el art. 39 CE.

Finalmente en este apartado citaremos que tanto parejas de hecho como uniones estables surgen como respuesta a las siguientes situaciones: parejas que sólo quieren convivir con sus propias reglas sin someterse a la normativa establecida para el matrimonio, y por otro lado a las parejas que no pueden casarse ya sea por impedimento legal o por vínculo matrimonial existente o casados bajo sus costumbres o religiones, su matrimonio religioso no gozan de reconocimiento de efectos civiles en España. A mayor abundamiento es importante citar la Sentencia del Tribunal Europeo de Derechos Humanos (TEDH) recaída en el Asunto Muñoz Díaz c. España, de 8 de diciembre de 2009 en la que se reconocen efectos civiles al matrimonio celebrado bajo el rito de la etnia gitana.

\section{La familia en el ámbito internacional}

Una vez revisado el sistema familiar interno daremos un paso más allá y analizaremos la protección de la familia en el derecho internacional. Para esto debemos tener presente que:

El Derecho internacional privado, regula lo referente a los matrimonios mixtos y esta regulación se hace extensible a las parejas mixtas. Se entiende como matrimonios mixtos aquel matrimonio celebrado entre dos personas con un elemento de extranjería configurado generalmente por la nacionalidad de cada cónyuge. Estos supuestos se encuentran regulados por el artículo 9.2. CC. referente a los efectos personales y patrimoniales del matrimonio mixto.

Una vez identificado el elemento de extranjería, podemos avanzar y analizar el proyecto migratorio de la familia mixta, es decir, si por motivos de trabajo uno de los cónyuges se traslada a un tercer país, país de destino, donde establecerá su residencia y posteriormente llevará a los demás miembros de su familia. Con la ejecución de su proyecto migratorio se configura la familia transnacional, entendida como aquella familia que se desplaza desde su país de origen hacia un tercer país, denominado país de destino, donde continuará con su vida familiar. 
Dicho lo anterior, el familiar residente en el país de destino pasa a ser titular del derecho a la reagrupación familiar, derecho que permite llevar a sus familiares al país de destino donde actualmente resida.

En cuanto a los familiares beneficiarios del derecho a la reagrupación familiar la LODYLE en ya citado artículo 17 se menciona quienes son los familiares reagrupables o beneficiarios del derecho a reagrupación familiar. En el siguiente apartado Analizaremos los derechos que sirven de base para la configuración de la familia transnacional y el derecho a la reagrupación familiar.

\section{El derecho a vivir en familia y derecho a la libre circulación de personas}

Visto el contexto de las familias transnacionales, es oportuno traer a colación lo comentado en el apartado IV de este estudio, en el que analizamos los modelos de familia reconocidos en el ordenamiento civil español, se dijo que el legislador, además de la familia nuclear, recoge en sus dispositivos legales a otros modelos de familia que también gozan de la protección contenida en el art 39 CE.

En el plano del Derecho internacional, se analizó a la familia en el ámbito del derecho internacional privado, familias mixtas y en el ámbito del derecho de extranjería citamos la reagrupación familiar como presupuesto de la familia transnacional.

Cuando hablamos de reagrupación familiar en España (RAVETLLAT BALLESTE, Isaac), se ha de tener en cuenta la interacción entre dos regímenes. El régimen comunitario aplicable cuando uno o ambos familiares son nacionales de un país miembro de la Unión Europea (UE). Y el otro régimen es el general de extranjería, aplicable cuando ambos los familiares son nacionales de terceros países no miembros de la UE. Para mayor abundamiento la sentencia del Tribunal de Justicia de la Unión Europea (TJUE), de fecha 27 de julio de 2006, se pronuncia en cuanto a los elementos configurativos de la reagrupación familiar.

Ambos regímenes se nutren del derecho a vivir en familia, dispuesto en el artículo 12 de la Declaración Universal de los Derechos Humanos (DDHH) y en el artículo 8 del Convenio Europeo de Derechos Humanos (CEDH), directrices que informan tanto a la Directiva comunitaria 2004/38 CE del Parlamento Europeo y del Consejo, de 29 de abril, sobre reagrupación familiar del régimen comunitario, la Directiva 2003/86 CE, del 22 de septiembre, sobre el Derecho a la reagrupación familiar y a la LODYLE. Es oportuno indicar que existe una flexibilidad en el régimen comunitario en cuanto a los requisitos exigidos a los familiares reagrupantes y esta flexibilidad responde a que los ciudadanos de la UE, además del derecho a vivir en familia son titulares del derecho a la libre circulación de personas dentro del territorio de la UE; siendo este derecho extensible a sus familiares nacionales de terceros países no miembros de la UE. Es decir, la reagrupación familiar de esa familia transnacional se concreta fácilmente por el ejercicio a la libre circulación y en cambio en el régimen general únicamente por el derecho a vivir en familia, debiendo acreditar entre otros la validez del vínculo afectivo y familiar (MONTILLA MARTOS, José).

Dicho todo lo anterior no puedo dejar de manifestar que a pesar de contar con una vasta estructura jurídica de protección a la familia en el ordenamientos jurídicos nacional e internacional. No sucede lo mismo en el ámbito nacional ya que aún queda pendiente la tarea 
de desarrollar las garantías de los familiares en cuanto al ejercicio del derecho a vivir en familia.

Por su parte las familias transnacionales (MOYA MALAPEIRA, David), especialmente las que tienen miembros nacionales de países no miembros de la UE, no pueden ejercer fácilmente el derecho a vivir en familia e incluso se encuentran con muchos obstáculos (burocráticos o razones que responden a políticas migratorias) que se manifiestan a través de la exigencia de requisitos principalmente de acreditación del vínculo familiar y obligando con ello a la judicialización del ejercicio de tal derecho. No olvidemos que el legislador europeo dotó de carácter fundamental al multicitado derecho a vivir en familia y sin embargo para el legislador español este derecho sólo goza de un carácter legal, ver sentencia del TC 236/2007.

\section{Conclusiones}

1. Los cambios sociales en el ámbito familiar, responden generalmente a factores como la incorporación de la mujer al mercado de trabajo, cambio en los roles y áreas domésticas, crisis matrimoniales y factores migratorios lo cual ha generado la manifestación de nuevos modelos de familia como son: las familias extensas, las familias de grupo recompuesto y las familias transnacionales. Estos modelos de familia están presentes en nuestra sociedad y cada vez en mayor número, lo cual indica la superación de la concepción clásica de familia (nuclear o matrimonial) entendida como la formada por padres casados y sus hijos.

2. En el ordenamiento jurídico español, se ha superado el concepto clásico de familia matrimonial toda vez que la doctrina constitucional interpreta el artículo 32 y 39 CE de manera separada, reconociendo así la protección de la familia, dispuesta en el art. 39 CE, no sólo a la familia matrimonial sino a otra forma de convivencia basada en la solidaridad y convivencia. Asimismo el legislador ha tenido en consideración las nuevas formas de residencia y convivencia siendo prueba de ello, a nivel autonómico, lo referente a familia no matrimonial "more uxorio", la variada legislación sobre parejas de hecho y uniones estables de pareja (13 legislaciones distintas) y en cuanto a grupos recompuestos, en la LODYLE podemos indicar que el art. 17.1.b. regula lo referente a la reagrupación familiar de los hijos del cónyuge o pareja de hecho.

3. En cuanto al derecho internacional, como consecuencia de los flujos migratorios nos encontramos frente a dos situaciones que afectan a la familia: - En primer lugar en el ámbito del derecho internacional privado lo referente a matrimonios mixtos y parejas mixtas y sus correspondientes efectos personales y patrimoniales que son regulados mediante la norma de conflicto contenida en el art. 9.2. CE., y

En segundo lugar, en el ámbito del derecho de extranjería, las familias transnacionales y su extensa estructura diseñada alrededor de los derechos a vivir en familia, para los ciudadanos nacionales de terceros países no miembros de la UE y del derecho a la libre circulación para los ciudadanos nacionales de países miembros de la UE.

4. Finalmente, indicar que las incidencias y conflictos en cuanto al reconocimiento de derechos a los nuevos modelos de familia y su pleno ejercicio del derecho a vivir en familia están siendo resueltos principalmente por el TEDH. A nivel interno, los conflictos son resueltos primordialmente por el $\mathrm{TC}$, tribunal que dota de un carácter no fundamental al derecho a vivir en familia y esta situación nos conduce a una mayor expectativa en cuanto a 
la entrada en vigor del Tratado de Lisboa, con el que se intentará homogeneizar y dar mayor coherencia a los criterios de los distintos en el marco de la UE.

\section{BIBLIOGRAFIA}

AJA ELISEO, MONTILLA MARTOS JOSE A., Los derechos de los inmigrantes en España. Instituto de Dret Público. Ed. Tirant lo Blanch. Valencia, 2009.

AJA, ELISEO. El Estado Autonómico. Federalismo y hechos diferenciales. $2^{a}$ Edición. Instituto de Derecho. Público. Ed. Tirant lo Blanch. Valencia, 2009.

ALONSO PEREZ, JOSE IGNACIO. El reconocimiento de las uniones no matrimoniales en la Unión Europea. Análisis y sinopsis de las leyes autonómicas en vigor. Ed. Bosch. Barcelona, 2007

FERNANDEZ ROZAS, JOSE C., SANCHEZ LORENOZ SIXTO. Derecho Internacional Privado. $4^{a}$ edición. Ed. Thomson Civitas - Aranzadi. Navarra, 2007.

LAFONT NICUESA, LUIS, Extranjería. Ed. Tirant lo Blanch. Valencia, 2008.

MOYA MALAPERIA, DAVID. Comentarios a la reforma de la Ley de extranjería (LO 2/2009). Instituto de Dret Público. Ed. Tirant lo Blanch. Valencia 2011.

RAVETLLAT BALLESTE, ISAAC. La reagrupación familiar. Ed. Bosch. Barcelona 2011.

ROCA TRIAS, ENCARNACION. Estudio comparado de la regulación autonómica de las parejas de hecho: soluciones armonizadoras. Ed. Consejo general del Poder Judicial. Madrid, 2005.

SANCHEZ CALERO, FRANCISCO JAVIER. Curso de Derecho Civil IV, Derechos de Familia y Sucesiones. Cuarta edición. Ed. Tirant lo Blanch. Valencia 2005.

SATORRAS FIORETTI, ROSA MARÍA. Lecciones de Derecho Eclesiástico del Estado. $3^{\mathrm{a}}$ edición. Ed. J.M. Bosch. Barcelona, 2004.

VILLAGRASA ALCAIDE, CARLOS., RICO IÑIGO, MARTA. Derecho de Familia. Ed. Bosch. Barcelona 2011. 


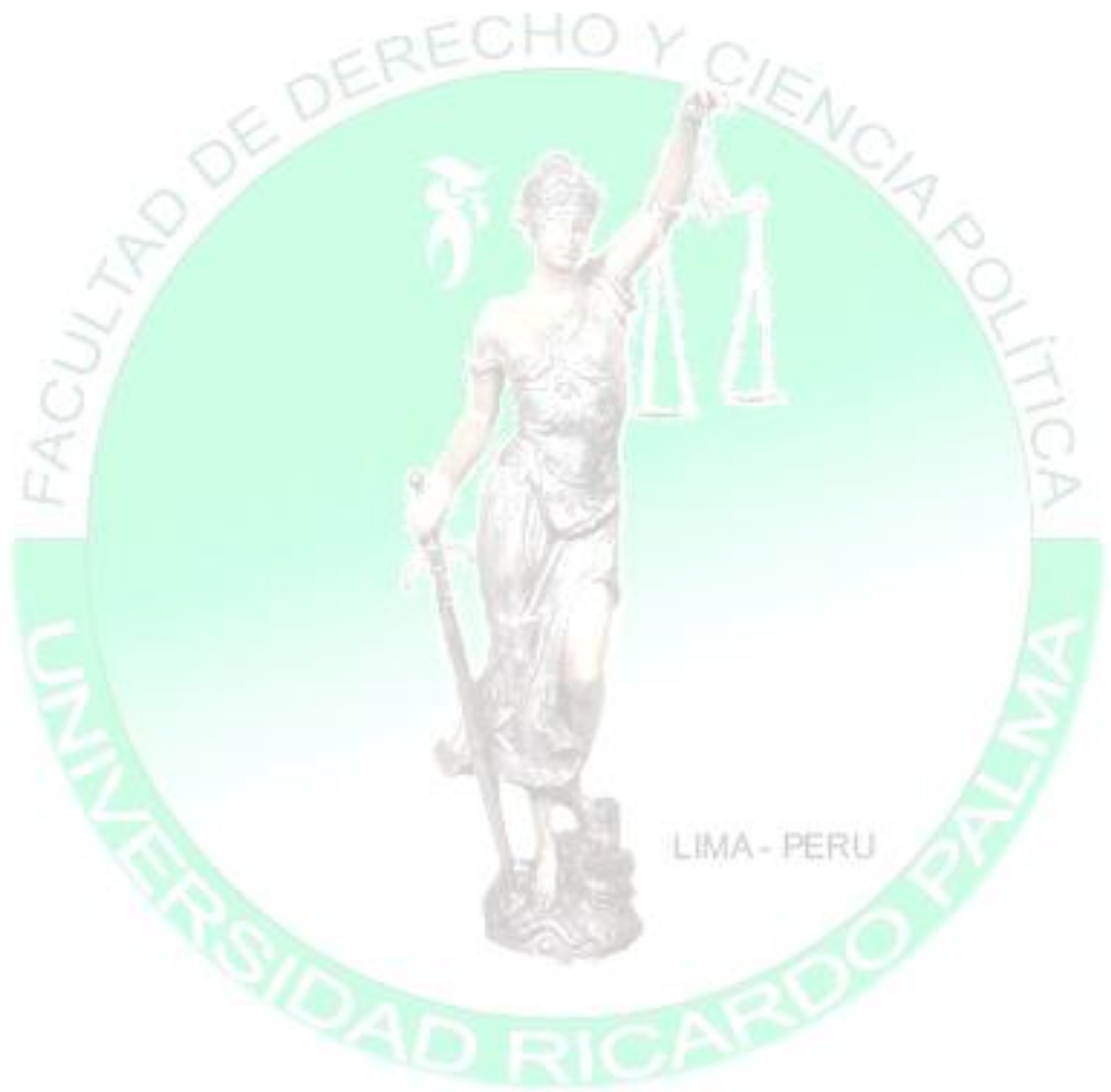

